\title{
Coastal Change During Hurricane Isabel 2003
}

On September 18, 2003, Hurricane Isabel made landfall on the northern Outer Banks of North Carolina. At the U.S. Army Corps of Engineer's Field Research Facility in Duck, $125 \mathrm{~km}$ north of where the eyewall cut across Hatteras Island, the Category 2 storm generated record conditions for the 27 years of monitoring. The storm produced an $8.1 \mathrm{~m}$ high wave measured at a waverider buoy in $20 \mathrm{~m}$ of water and a $1.5 \mathrm{~m}$ storm surge.

As part of a program to document and better understand the changes in vulnerability of the Nation's coasts to extreme storms, the U.S. Geological Survey (USGS), in collaboration with the National Aeronautics and Space Administration (NASA), surveyed the impact zone of Hurricane Isabel. Methods included pre- and post-storm photography, videography, and lidar.

Hurricane Isabel caused extensive erosion and overwash along the Outer Banks near Cape Hatteras, including the destruction of houses, the erosion of protective sand dunes, and the creation of island breaches. The storm eroded beaches and dunes in Frisco and Hatteras Village, southwest of the Cape. Overwash deposits covered roads and filled homes with sand. The most extensive beach changes were associated with the opening of a new breach about $500 \mathrm{~m}$ wide that divided into three separate channels that completely severed the island southwest of Cape Hatteras. The main breach, and a smaller one several kilometers to the south (not shown), occurred at minima in both island elevation and island width.

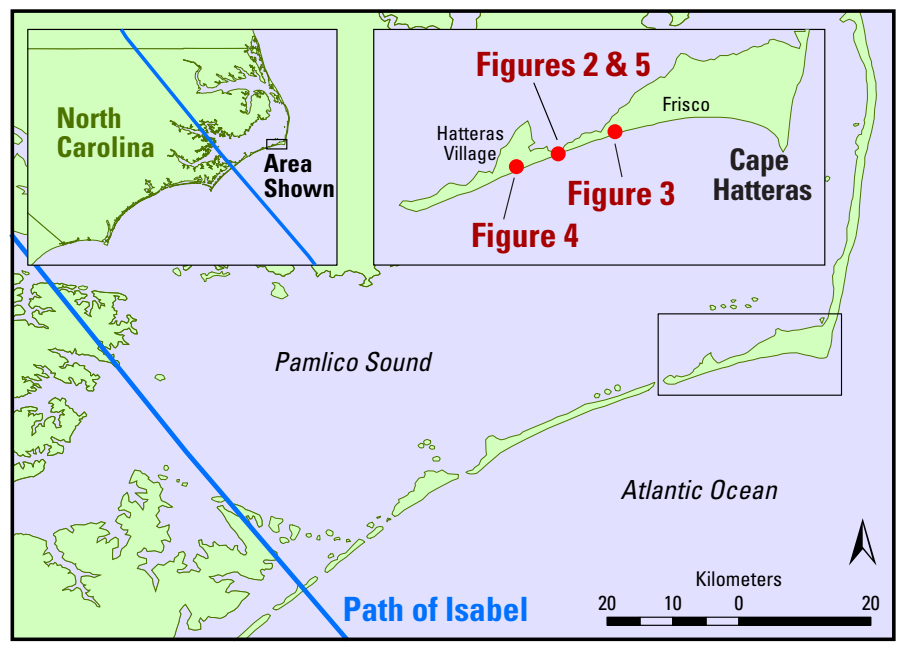

Figure 1. Map showing the track of Hurricane Isabel across the North Carolina coast.

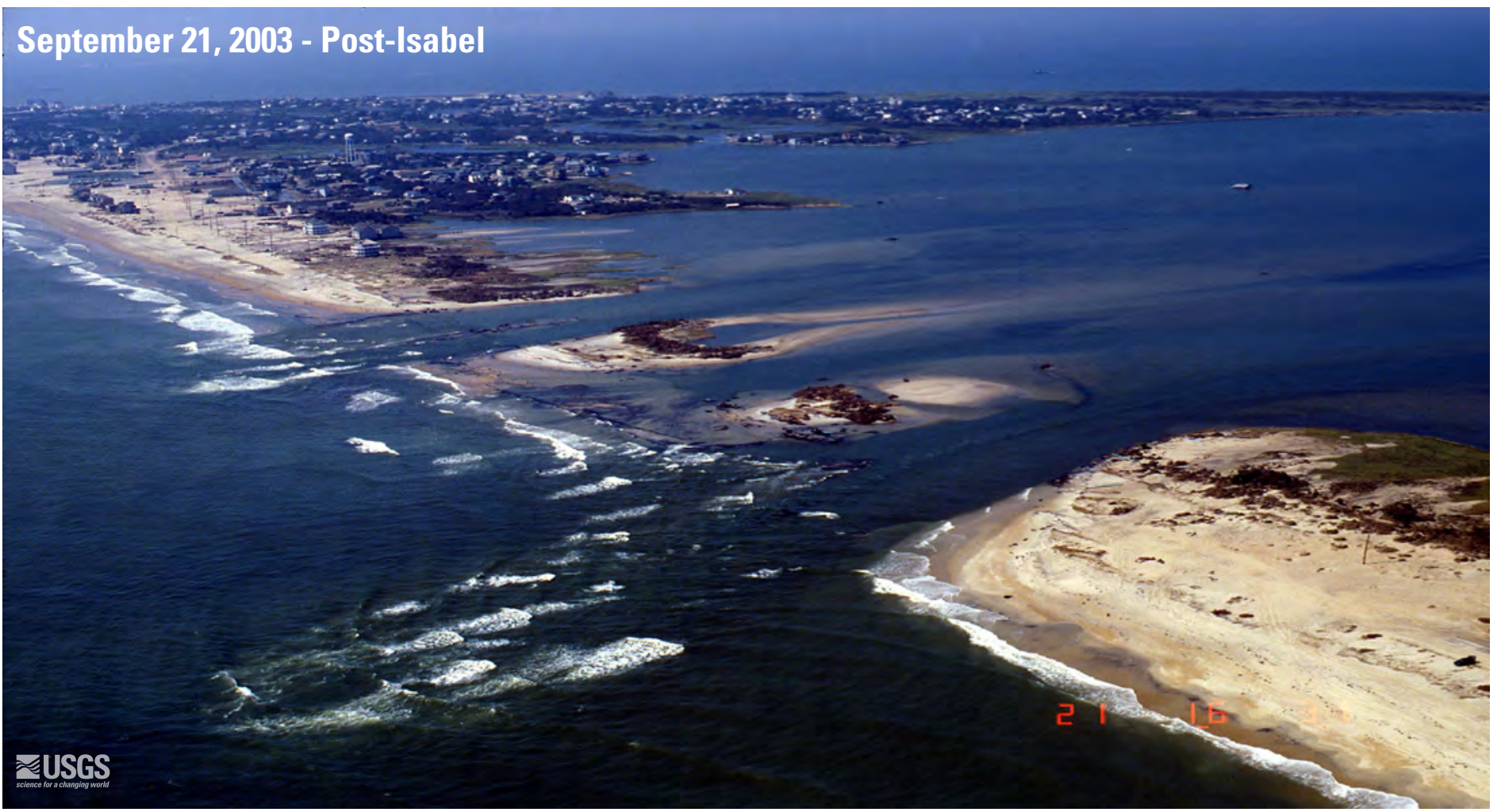

Figure 2. Hurricane Isabel opened a breach in the island southwest of Cape Hatteras. Combined waves and storm surge attacked the island where the dunes were lowest and the island was narrowest. 

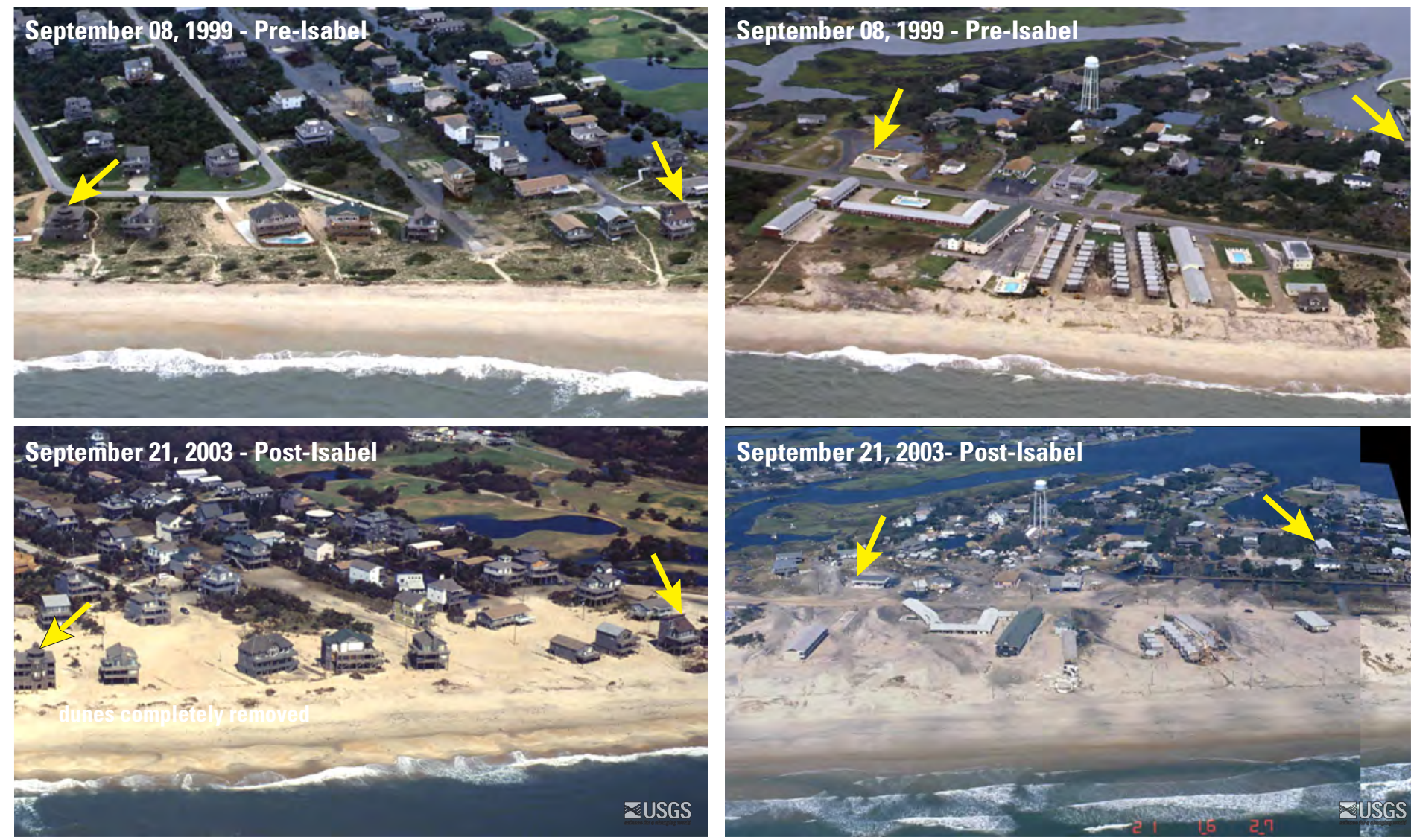

Figure 3. Frisco, North Carolina. USGS aerial photography taken before and after the landfall of Hurricane Isabel. Storm surge and waves overwashed the dunes located seaward of the first row of houses and deposited that sand across the island. (Arrows in all images point to the same features.)

Figure 4. Hatteras Village, North Carolina. USGS aerial photography taken before and after the landfall of Hurricane Isabel. Storm surge and waves destroyed and inundated the dunes protecting the hotels. The water washed the buildings from their foundations and covered roads with sand. (Arrows in all images point to the same features.)
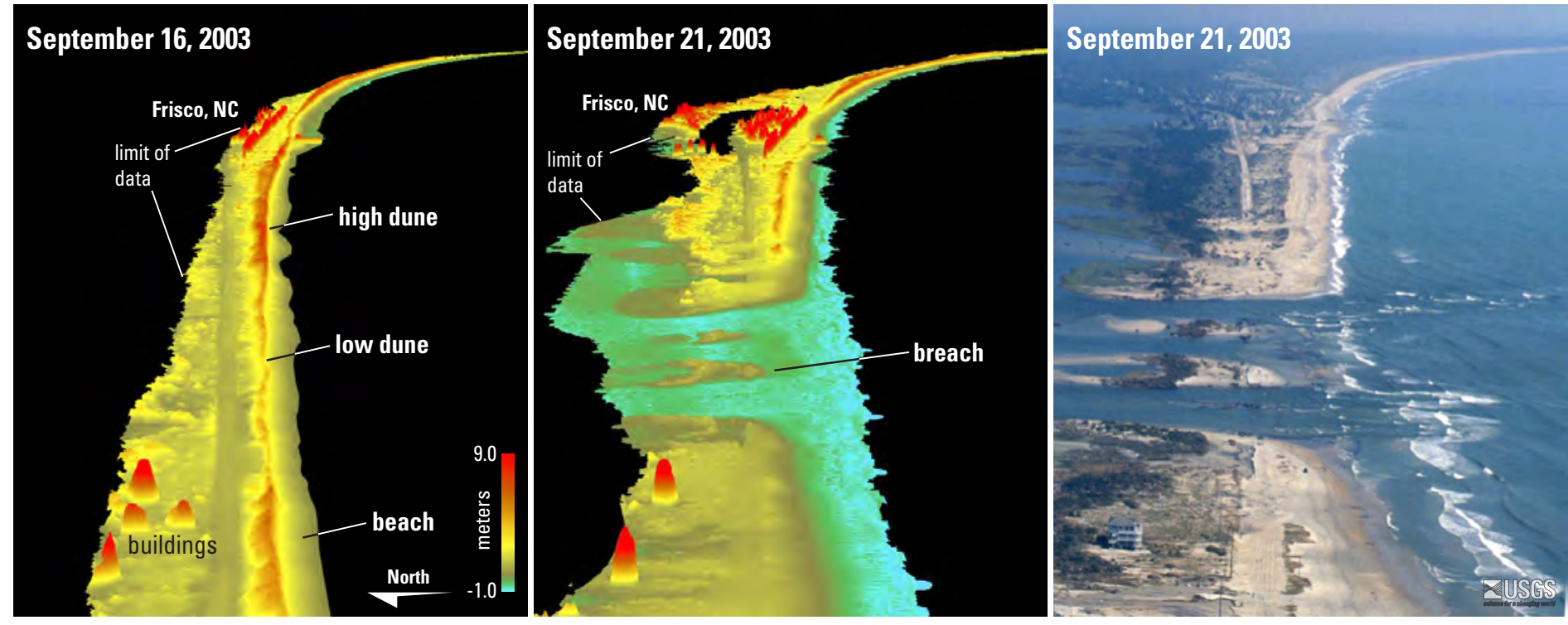

Figure 5. Hatteras Island, North Carolina. Analyses of NASA Experimental Advanced Airborne Research Lidar (EAARL) data from the island show extensive beach changes and dune erosion, as well as the destruction of infrastructure and buildings. Upper right and center: Lidar images show high-resolution topography of a portion of the coast measured with NASA's EAARL before and after Hurricane Isabel. The different colors indicate different elevations, where in the warmer colors represent higher elevations (see scale). Right: An oblique photograph taken by USGS on the same day as the post-storm lidar survey.

Author: Karen L. M. Morgan, USGS kmorgan@usgs.gov 727-803-8747 x 3037

Project Contact: Asbury (Abby) Sallenger, USGS asallenger@usgs.gov 727-803-8747 x 3015

http://coastal.er.usgs.gov/hurricanes/ 